\title{
Dampened expectations in the Phillips Curve: a note
}

\author{
Charles Dennery *
}

July 2019

\begin{abstract}
Dampened inflation expectations have a significant impact on the New Keynesian Phillips Curve. This dampening not only flattens the long run Phillips Curve, but it can also lead to a bias in the estimation of its short run slope. It also affects the response of a small NK model to demand shocks, and affects the optimal monetary policy: in particular, the price targeting result of the Ramsey policy is violated when there is dampening.

JEL codes: E31, E52

Keywords: anchored expectations, Phillips curve, Ramsey policy
\end{abstract}

\section{Introduction}

The Phillips Curve is central to macroeconomics but its shape has been questioned recently. Blanchard (2016) argues against a vertical or near-vertical long-run Phillips curve: it has allegedly become flatter, largely due to inflation expectations anchored at zero or low levels. The inflation expectation used in the Phillips Curve is a long-run expectation which is anchored around a reference point, and only adjusts partially to changes in short-run expectations. As such, the effect of short-run inflation expectations is largely dampened, and this would imply a real trade-off between output and inflation in the long run.

The Phillips Curve is often assumed to be accelerationist or near accelerationist: if current inflation increases one-to-one with short-run inflation expectations, this implies that the output gap is related to the acceleration of inflation (in the New Keynesian Phillips Curve, inflation doesn't exactly increase one-toone with expectations, but the pass-through is close to unity, implying a near accelerationist curve). But if short-run inflation expectations are dampened, or play a dampened role, in the sense that they matter less for agents (and hence current inflation) - then the Phillips Curve is no longer accelerationist. The rate of inflation - and not only its acceleration - matters for the output gap.

*Ecole Polytechnique Federale de Lausanne. Email: charles.dennery@epfl.ch. I am grateful to Gianluca Benigno, Ricardo Reis, Wouter den Haan, Luisa Lambertini and Florin Bilbiie, as well as Kevin Sheedy and Francesco Zanetti, for advice and comments. All errors are mine. 
When estimating a short run Phillips Curve, ignoring this dampening leads to a reduced coefficient on output/unemployment. The reason for this flattening bias is simple: since current inflation is correlated with output (or unemployment), expectations of future inflation are correlated with future output (unemployment), which is itself correlated with current output (unemployment). Mismeasuring the role of expectations necessarily biases the slope coefficients.

Explanations for dampened expectations fall in two categories. One is behavioral: inflation expectations are either anchored around a reference (Blanchard, 2016), or agents are myopic about the future (Gabaix, 2018). The other relies on product creative destruction in the price Phillips Curve (see Bilbiie et al. $(2008,2014)$ ) or job turnover in the wage Phillips Curve (Snower and Tesfaselassie (2017), Lepetit (2018)). These papers have looked at the long term consequences: the long-run Phillips Curve and the optimal inflation target. On the contrary, my paper focuses on the short run consequences of this dampening.

This paper also belongs to the stream of literature that reassesses the New Keynesian model in light of the Great Recession and the Zero Lower Bound. While this paper introduces an extra discount factor in the Phillips curve, other papers have introduced a discount factor in the Euler equation instead, to explain the forward guidance puzzle (see McKay et al. $(2016,2017)$ and Del Negro et al. (2015)). The interaction between a discounted Phillips curve and a discounted Euler equation has been partially studied by Gabaix (2018).

I first look at the interaction between dampened inflation expectations and the slope of the short run Phillips Curve. I then look at the consequence for a small New Keynesian model, in terms of the response to supply and demand shocks. Finally I revisit the Ramsey optimal stabilisation policy in suh a setup.

\section{Dampened inflation expectations}

The New Keynesian Phillips Curve is typically written with inflation $\pi_{t}$ and the output gap $y_{t}$ (or wage inflation and cyclical unemployment):

$$
\pi_{t}=\kappa y_{t}+\beta \mathrm{E}_{t}\left[\pi_{t+1}\right]
$$

In this setup $\beta$ is the risk-less discount factor and $\kappa$ the output coefficient. Suppose, however,that the true model features dampened inflation expectations:

$$
\pi_{t}=\kappa y_{t}+\beta \delta \mathrm{E}_{t}\left[\pi_{t+1}\right]
$$

$\delta \in(0,1)$ is the dampening factor. It can come from anchored expectations (Blanchard, 2016), a behavioral bias (Gabaix, 2018), product creative destruction (Bilbiie et al. (2014), or job turnover (Snower and Tesfaselassie, 2017). In such cases the long run version of (2) implies a flatter long-run Phillips curve, and it is no longer vertical or nearly vertical as in the standard case: $\bar{\pi}=\frac{\kappa}{1-\beta \delta} \tilde{y}$. Dampened inflation expectations do not directly affect $\kappa$, the slope of the short run PC. But it can nevertheless lead to a downward bias in its estimation. 


\subsection{Short run bias}

Suppose that we are estimating eq (1) but eq (2) is the true model. Even though it is not the right model, estimating eq (1) will provide an unbiased estimate of $\kappa$ if the output and inflation expectation coefficient are jointly estimated (of course the estimated coefficient for expectations will estimate $\beta \delta$ not $\beta$ ). But eq (1) is often estimated with a calibrated $\beta$, which doesn't account for any dampening. This leads to a biased estimation of $\kappa$ if the true model is eq (2) and the output gap (or cyclical unemployment) is serially correlated.

For example, let us estimate a reduced form Phillips Curve featuring only the output gap and current inflation $\pi_{t}=\tilde{\kappa} y_{t}$, and then back out the structural parameters by relying on the auto-regressive properties of the output gap. This approach has been followed, eg, in Gali (2011). ${ }^{1}$ Assume that output is serially correlated: ${ }^{2} y_{t}=\rho_{y} y_{t-1}+u_{t}$, with $u_{t}$ a mean-zero shock. Iterate eq (2) forward:

$$
\pi_{t}=\kappa y_{t}+\beta \delta \mathrm{E}_{t}\left[\pi_{t+1}\right]=\kappa \sum_{k \geq 0}(\beta \delta)^{k} \mathrm{E}_{t} y_{t+k}=\frac{\kappa}{\left(1-\rho_{y} \beta \delta\right)} y_{t}
$$

Estimating this reduced-form equation provides an estimate of $\tilde{\kappa}=\frac{\kappa}{\left(1-\rho_{y} \beta \delta\right)}$ from which $\kappa$ can be uncovered if $\beta, \delta$ and $\rho_{y}$ are known. But if the dampening factor is not accounted for (ie, having $\delta=1$ ), the estimate of $\kappa$ will be biased.

Property 1 If $\kappa$ is the true output coefficient, the estimated $\kappa^{*}$ is smaller

$$
\kappa^{*}=\frac{\left(1-\beta \rho_{y}\right)}{\left(1-\rho_{y} \beta \delta\right)} \kappa<\kappa
$$

Hence one can see immediately that the dampening factor $\delta$ will affect the slope of a traditional, reduced-form, Phillips Curve displaying only current inflation and output, $\pi_{t}=\tilde{\kappa} y_{t}$. A non-linear estimation of the Phillips Curve using the reduced form equation above and the auto-regressive properties of the output gap (or cyclical unemployment) to back out the slope of the true Phillips Curve will lead to a biased estimate if the wrong model without $\delta$ is estimated. ${ }^{3}$

The same bias occurs if equation (1) is directly estimated and a wrong restriction is imposed for the coefficient $\beta$. This is the case in the empirical estimates of Gali and Gertler (1999), where they use marginal costs instead of the output gap. They estimate $\pi_{t}=\lambda m c_{t}+\beta E \pi_{t+1}$. The estimated coefficient of marginal costs, $\lambda$, depends on the assumption about the coefficient of future inflation, $\beta$. When this coefficient is restricted to $\beta=1$, the estimated value of $\lambda$ is smaller than when there is no restriction and $\beta$ takes a lower value. ${ }^{4}$

\footnotetext{
${ }^{1}$ Gali (2011) estimates an hybrid wage Phillips Curve with unemployment. As unemployment is assumed to be $\mathrm{AR}(2)$, a reduced form Phillips Curve without inflation expectations is first estimated, before backing out the structural parameters of the true hybrid PC.

${ }^{2}$ Assuming an AR(1) process allows for simple expressions for the source and amplitude of the bias. Assuming a more sophisticated process changes the expressions but not the logic.

${ }^{3}$ The same drawback would obviously apply to any joint estimation of a larger model, if inflation expectations are dampened but the estimated model doesn't account for it.

${ }^{4}$ The same logic would apply if an hybrid Phillips curve as in Gali and Gertler (1999) was estimated with a restriction on the coefficient of inflation expectations: it would create a bias in the estimation of other parameters.
} 


\subsection{Demand and supply shocks}

I will now examine how this modified Phillips Curve changes the response of output and inflation to shocks in a simple New Keynesian framework.

Let me look at a standard Euler equation: in log-linear form,

$$
y_{t}=E_{t} y_{t+1}-\frac{1}{\sigma}\left(i_{t}-E_{t} \pi_{t+1}\right)
$$

It can be combined with a Taylor rule

$$
i_{t}=\phi_{\pi} \pi_{t}+\phi_{y} y_{t}
$$

$\phi_{\pi}$ and $\phi_{y}$ are the inflation and output coefficients. While McKay et al. (2016, 2017) or Del Negro et al. (2015) have a modified Euler equation, I do not look at this modification here because this equation becomes isomorphic to a standard Euler equation with modified parameters, once combined with a Taylor rule. ${ }^{5}$

With my Phillips Curve, the dynamics, incorporating simple shocks, write:

$$
\begin{aligned}
y_{t} & =E_{t} y_{t+1}-\frac{1}{\sigma}\left(\phi_{\pi} \pi_{t}+\phi_{y} y_{t}-E_{t} \pi_{t+1}\right)+u_{t} \\
\pi_{t} & =\beta \delta E_{t} \pi_{t+1}+\kappa y_{t}+v_{t}
\end{aligned}
$$

The fist equation is often thought as a demand equation, while the second is a supply equation. $u_{t}$ is a demand shock - coming either from a shock to the natural rate of interest, or from a monetary policy shock - while $v_{t}$ is a supply shock - generated either by a productivity or by a cost-push (markup) shock.

\section{The role of persistence}

It is only with persistent shocks that turnover will bring significantly different impulse responses to supply and demand shocks. It is easy to see why. If there is a transitory (white noise) supply or demand shock today, future expected variables are not affected, $E_{t} \pi_{t+1}=E_{t} y_{t+1}=0$. Whether there is a coefficient $\beta$ or $\beta \delta$ in the Phillips Curve is irrelevant, as the expected inflation is zero. On the other hand, if the supply or demand shock is $A R(1)$ with $\rho \approx 1$, then $E_{t} \pi_{t+1} \approx \pi_{t}$. The Phillips Curve becomes $(1-\beta \delta) \pi_{t} \approx+\kappa y_{t}+v_{t}$ and is flatter with $\delta<1$ than normally. Output becomes more sensitive to demand shocks.

\footnotetext{
${ }^{5}$ In their modified Euler equation, $y_{t}=\gamma E_{t} y_{t+1}-\frac{1}{\sigma}\left(i_{t}-E_{t} \pi_{t+1}\right)$ with $\gamma \in[0,1]$ the dampening factor of the Euler equation. While it has strong implications at the Zero Lower Bound (where the Taylor rule does not apply), it is easy to see that when $\gamma \neq 1$, the modified equation can still be rearranged to appear as a standard Euler equation, without any dampening: $y_{t}=E_{t} y_{t+1}-\frac{1}{\sigma \gamma}\left(\phi_{\pi} \pi_{t}+\left(\phi_{y}+(1-\gamma) \sigma\right) y_{t}-E_{t} \pi_{t+1}\right)$

Hence, when a modified Euler equation (with dampening factor $\gamma<1$ ) is combined with a Taylor rule, the behavior is isomorphic to one with a lower elasticity of intertemporal substitution $(\gamma \sigma$ instead of $\sigma)$ and a higher output coefficient in the Taylor rule $\left(\phi_{y}+(1-\gamma) \sigma\right.$, instead of $\phi_{y}$ ). Once this equation is combined with a standard Phillips Curve into the basic New Keynesian model, the dampening has the same effect as increasing the output coefficient: The model would show very similar responses to interest rate shocks or cost push shocks.
} 

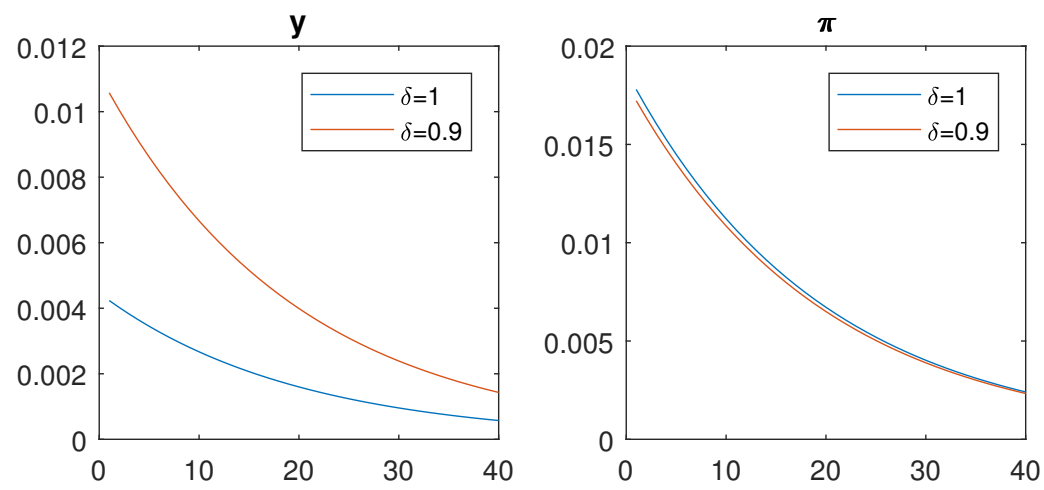

Figure 1: $y$ and $\pi$ in response to a persistent demand shock
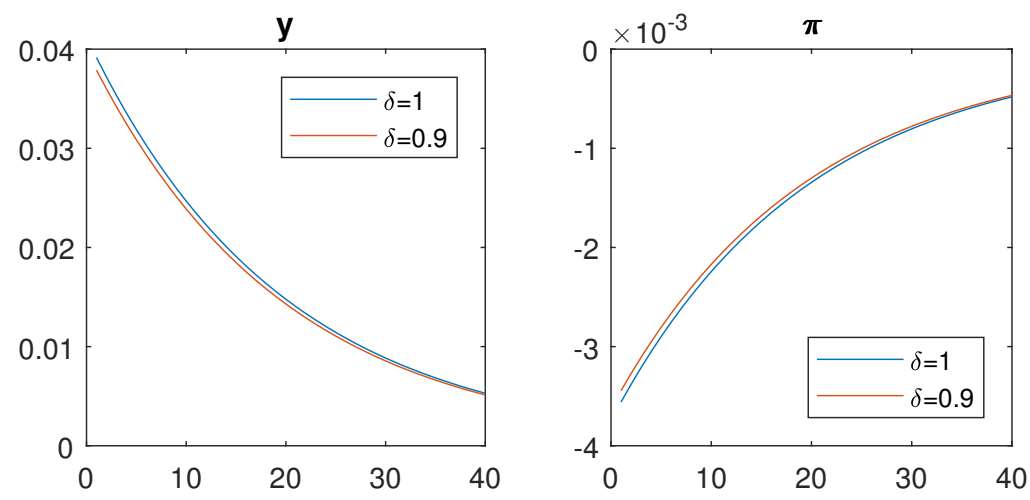

Figure 2: $y$ and $\pi$ in response to a persistent supply shock

Figures 1 and 2 display the impulse response functions of output and inflation to persistent demand and supply shocks respectively. The model is calibrated with $\sigma=1, \kappa=0.025, \phi_{\pi}=1.5$ and $\phi_{y}=0$. The shocks are very persistent $(\rho=0.95)$, and the turnover/dampening factor is set to 1 and 0.9 respectively.

One can see how turnover and dampened inflation expectations only have a significant impact on the response of output to persistent demand shocks. As hinted before, this is because turnover makes the supply curve flatter in the presence of persistent shocks. A demand shock has a bigger impact on output when the supply curve is flatter. This implies that for an observed fluctuation in output, the underlying fluctuation in the natural rate of interest is not as high as what the standard model would predict. Hence turnover and dampened inflation expectations significantly matter when the natural rate of interest is depressed for a while (a persistent negative demand shock) or when monetary policy persistently undershoots as compared to its baseline Taylor rule. ${ }^{6}$

\footnotetext{
${ }^{6}$ The case of the Zero Lower Bound is different as the Taylor rule no longer applies there.
} 


\subsection{Price/wage targeting}

As we will see, introducing dampened expectations into a standard New Keynesian model has strong implications for the optimal Ramsey policy. Normally, price (wage) targeting is optimal for the Ramsey policy: even with steady state distortions, the long run optimal level of inflation is zero; while inflation reacts to cost push shocks in the short run, this is accompanied by deflation in the future, so that there is full mean reversion of the price level. There is long-run price targeting in response both to long term distortions and short term cost push shocks. But with dampened expectations, price targeting is no longer optimal: long run inflation is non zero if there are steady state distortions; in response to cost push shocks, some deflation in the future offsets the initial response of inflation, but there is no longer full mean reversion of the price level.

Let me first define the aggregate welfare function, as in Gali (2008).

Property 2 The second order approximation of the aggregate utility is

$$
U=-\sum_{t \geq 0} \beta^{t}\left[\kappa \frac{\left(y_{t}-\bar{y}\right)^{2}}{2}+\epsilon \frac{\pi_{t}^{2}}{2}\right]
$$

I also assume an $A R(1)$ cost push shock $u_{t}$ in the Phillips curve:

$$
\pi_{t}=\kappa y_{t}+\beta \delta \mathrm{E}_{t} \pi_{t+1}+u_{t}
$$

Denoting $\lambda_{t}$ the Lagrange multiplier of the Phillips Curve at time $\mathrm{t}$, the Lagrangian of the optimal Ramsey policy is

$$
L=-\mathrm{E}_{0} \sum_{t=0}^{+\infty} \beta^{t}\left(\begin{array}{c}
\frac{1}{2}\left[\epsilon \pi_{t}^{2}+\kappa\left(y_{t}-\bar{y}\right)^{2}\right] \\
+\lambda_{t}\left(\pi_{t}-\beta \delta \mathrm{E}_{t} \pi_{t+1}-\kappa y_{t}-u_{t}\right)
\end{array}\right)
$$

Taking first order conditions and simplifying $\lambda_{t}, \epsilon \kappa \pi_{0}=\kappa\left(\bar{y}-y_{0}\right)$

and $\epsilon \kappa \pi_{t}=\kappa\left(\left(\bar{y}-y_{t}\right)-\delta\left(\bar{y}-y_{t-1}\right)\right)$. Used in the Phillips Curve, this shows that output $y_{t}$ follows a second order difference equation:

$$
\left(1+\kappa \epsilon+\beta \delta^{2}\right) y_{t}=\beta \delta \mathrm{E}_{t} y_{t+1}+\delta y_{t-1}+(1-\delta)(1-\beta \delta) \bar{y}-\epsilon u_{t}
$$

The steady state of output and inflation are zero only if $\delta=1$ :

$$
y^{*}=\frac{(1-\delta)(1-\beta \delta)}{(1-\delta)(1-\beta \delta)+) \epsilon \kappa} \bar{y} \quad \pi^{*}=\frac{(1-\delta) \kappa}{(1-\delta)(1-\beta \delta)+\epsilon \kappa} \bar{y}
$$

When $\delta=1, \epsilon \pi_{0}=\left(\bar{y}-y_{0}\right)$ and $\epsilon \pi_{t}=-\left(y_{t}-y_{t-1}\right)$, so we can integrate $\epsilon\left(w_{t}-w_{-1}\right)=\left(\bar{y}-y_{t}\right)$. Thus $w_{t}$ also follows a stationary difference equation (level targeting). With $\delta<1$, the wage level can no longer be integrated as a stationary variable. There is only partial mean reversion of the wage level.

Property 3 Long run level targeting is the optimal Ramsey policy only when $\delta=1$. When $\delta<1$, targeting the nominal wage level is no longer optimal. Long run inflation is non zero if there are steady state distortions. And in response to cost push shocks, some deflation in the future offsets the initial response of inflation, but there is no longer full mean reversion of the wage level (see fig 3). 

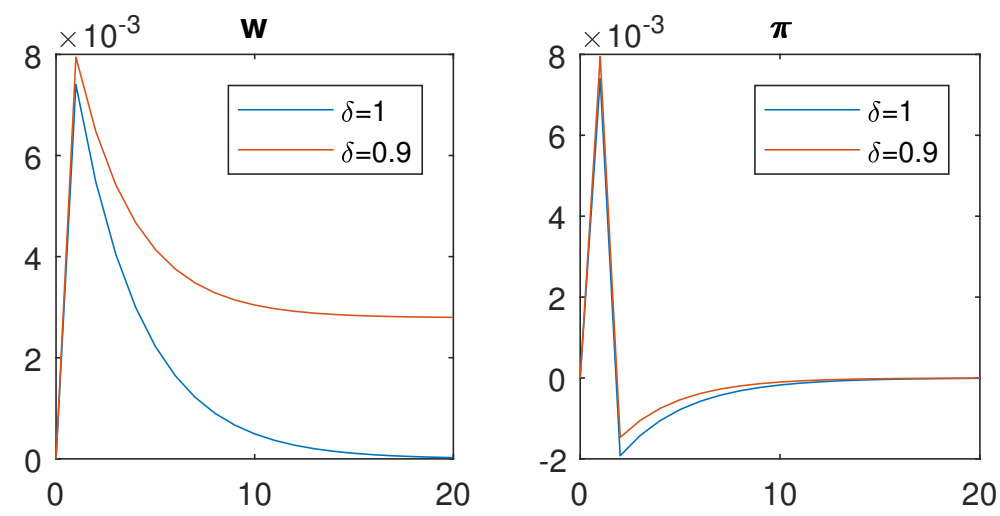

Figure 3: Ramsey policy in response to a wage cost-push shocks

The intuition is as follows: in the benchmark, by committing to give up some discretion in the future, the planner has some extra discretion in the present to offset cost push shocks, or an inefficient steady state. So that price (or wage) stability is optimal from today's perspective, but there is an incentive to renege tomorrow. With dampened expectations, workers are less responsive to commitments, so that the current gain in terms of commitment no longer offsets the inefficiency in the future. Thus, even with a credible commitment, inflation will always be used to offset cost push shocks or steady state inefficiencies.

\section{Conclusion}

In this note, I investigated some of the effects of dampened inflation expectations in the Phillips Curve. If the coefficient of future inflation is restricted in a standard NK Phillips Curve, this creates a bias on the estimate of the slope of the Phillips Curve, This dampening has important implications when one looks at the effect of persistent demand shocks in a small NK model: while the effect on inflation is very small, the dampening increases the response of output. I also showed how turnover breaks the optimality of price stability. Optimal Ramsey policy no longer targets the price level in response to cost push shocks.

\section{References}

[Bilbiie et al., 2014] Bilbiie, F., Ghironi, F., and Fujiwara, I. (2014). Optimal Monetary Policy with Endogenous Product Variety. Journal of Monetary Economics, 64:1-20.

[Bilbiie et al., 2007] Bilbiie, F., Ghironi, F., and Melitz, M. (2007). Monetary Policy and Business Cycles with Endogenous Entry and Product Variety. NBER WP 13199. 
[Blanchard, 2016] Blanchard, O. (2016). The US Phillips Curve: Back to the 60s? . Peterson Institute for International Economics.

[Del Negro et al., 2015] Del Negro, M., Giannoni, M., and Patterson, C. (2015). The Forward Guidance Puzzle. New York Fed Staff Reports 574.

[Gabaix, 2018] Gabaix, X. (2018). A Behavioral New Keynesian Model. mimeo.

[Gali, 2008] Gali, J. (2008). Monetary Policy, Inflation, and the Business Cycle: An Introduction to the New Keynesian Framework and Its Applications. Princeton University Press.

[Gali, 2011] Gali, J. (2011). The Return of the Wage Phillips Curve. Journal of the European Economic Association, 9(3):436-461.

[Gali and Gertler, 1999] Gali, J. and Gertler, M. (1999). Inflation dynamics: A structural econometric analysis. Journal of Monetary Economics, 44(2):195 -222 .

[Lepetit, 2018] Lepetit, A. (2018). The optimal rate of inflation with discount factor heterogeneity. Unpublished draft, FRSB.

[McKay et al., 2016] McKay, A., Nakamura, E., and Steinsson, J. (2016). The Power of Forward Guidance Revisited. American Economic Review, 106(10):3133-58.

[McKay et al., 2017] McKay, A., Nakamura, E., and Steinsson, J. (2017). The Discounted Euler Equation: A Note. Economica, 84(336):820-831.

[Snower and Tesfaselassie, 2017] Snower, D. and Tesfaselassie, M. (2017). Job Turnover, Trend Growth, and the Long-Run Phillips Curve. Macroeconomic Dynamics, 21(4):835-861. 